problems; it also undermines the earlier idea of special duties of care attaching to health workers.

These essays range over a familiar set of questions: abortion, euthanasia, autonomy, consent, resource allocation and testing, and vary in length (from 7 to 20 pages) and degree of philosophical sophistication. They have nothing to add in the way of reflective understanding of these issues, but are not redundant on that account, for having been written largely by health care professionals, they are, perhaps, more likely to engage the interest of similar readers than are 'applied' works by professional philosophers. The two longest and most extensively referenced essays are by the same author, Richard Bentall, on Values and Diagnosis and Compulsory Care. In the briefest contribution, Should My Baby Live?, Sylvia Parker movingly and effectively places a moral dilemma within a context of philosophical theories, thereby showing the complexity of the issue and the foolishness of the assumption that going 'philosophical' means finding a decision procedure.

There is a growing need for informed reflection on the ethics of health care which manages to achieve understanding while avoiding the incapacitating effect of abstract speculation. That need is most likely to be met by thoughtful practitioners such as the contributors to this collection. Deeper and wiser thinking is necessary but this is a good start to an ongoing series of publications.

JOHN HALDANE, Reader in Moral Philosophy, Director of the Centre for Philosophy and Public Affairs, University of St Andrews.

\section{Health Promotion: Models and Values}

\author{
R S Downie, Carol Fyfe, Andrew \\ Tannahill, 183 pages, Oxford, 1990, \\ Oxford Medical Publications, \\ $£ 25.00 \mathrm{hc}, £ 12.95 \mathrm{sc}$.
}

What makes health promotion worth doing? On which goals should health promoters set their sights? What's health promotion for? To outsiders these must seem peculiar questions. After all most professions know what their purposes are. It would be a contradiction in terms for a lawyer, or a bank manager, or an accountant to say:
'I do not understand the rationale of my work'. Nonetheless, strange as it will appear to the uninitiated, one of the central characteristics of the caring professions is massive uncertainty about basic principles and direction.

In highlighting this area of doubt, and in identifying such clear key questions, Robin Downie and his colleagues have done health promotion a great service. There is, amongst many health promoters, deep unease that 'something's wrong'. A considerable number of practitioners are perturbed that their role is unclear, and that crucial underlying questions are left untouched. The prevailing emphasis is on function, on doing, on performing, but nobody has yet properly asked: 'Why this function rather than that one?'. In other words no one has tackled the philosophy of health promotion.

Unfortunately, frustrated health promoters must wait a little longer. Despite defining the right area of study the authors fail to deliver the goods. The book is a prescription for 'good practice' rather than a dispassionate philosophical review. It quickly becomes a crusade for an authoritarian approach to health promotion. As such it is a clear exposition of the values and aims of this sort of health promotion, but it does not seriously examine the critical key questions.

The argument is that there are 'better and worse life-styles', and that the point of health promotion activity is to ensure that the 'better' life-styles flourish. This point of view is reinforced by another: that it is possible to distinguish between 'subjective' and 'objective' well-being. 'Subjective' well-being is not necessarily 'true' well-being. Even if an individual 'feels great for a lifetime' his or her well-being may be 'spurious' if it 'arises from influences which are overall detrimental to an individual's functioning or flourishing, and/or to society'.

The authors make few bones about their position, and are quite open about their preferences for 'the good life'. For example, they argue that antidepressants induce 'subjective' wellbeing, whereas financial and other social support for a depressed person can promote 'objective' well-being through the provision of life-skills. Most targets for 'health promoters' derived from medical priorities are accepted without question: smoking is bad, drinking too much is bad, avoiding immunisation is bad. In a passage which reveals much about the aims of the book, and the level of some of the debate, the authors pour scorn on the 'non-judgemental' approach to health promotion. They quote an earlier writing partnership on the topic, Linda Ewles and Ina Simnett:

In discussing the inadequacies of traditional health education they (Ewles and Simnett) state that it has sometimes involved (among other failings):

"... the imposition of medical values on the client. Frequently, this means the imposition of middle-class values on working-class people, and the ethical justification for this is doubtful. For example, losing weight and lowering blood pressure may be the most important thing to a doctor, but drinking beer in the pub with friends may be far more important to his overweight, middle-aged, unemployed patient. Who is to say which set of values is 'right' - the doctor or his patient? Whose life is it anyway?"

'Two points can be made here. First, if the client wants to lose weight then he ought to take the doctor's advice and cut down on his beer drinking. Otherwise, why consult the doctor at all? Secondly, the health promoter is presumably committed to believing that health is at least one important value, and so is also committed to believing that the client should take the doctor's advice.'

But it is pretty clear that the man in the excerpt from Ewles has not gone to the doctor about his weight, and that he does not wish to have or take the doctor's advice on the matter. Much worse, 'health' is not a single value, as the authors themselves point out earlier. Nor is it true, even if health were a single value, that a belief that health is a good thing necessarily means that a person should take medical advice, or will achieve 'health' if he or she does. Medical work is not always work for health, as countless sociological and philosophical studies have shown.

Health Promotion: Models and Values is a disappointment. Time after time it raises fascinating questions, yet consistently fails to give them the depth of attention they deserve. The book acknowledges that there are different approaches to health promotion, opts for one only, and then shouts rather than argues for it. What is required, for an insightful philosophical investigation into health promotion (which is now needed more than ever), is the 'bird's eye view' promised in the publisher's blurb, not a campaign from within.

DAVID SEEDHOUSE,

Reader in Ethics, Lancashire Polytechnic. 